\title{
The Mathematical Model of Seed Movement on a Concave Profile Rib
}

\section{Khayrullo Sharipov, Khamit Akhmedxodjayev, Mukhammadjon Tojiboyev, Olimjon Sarimsakov*}

Department of Technology of Primary Processing of Natural Fibers, Namangan Institute of Engineering and Technology, Namangan, Uzbekistan

Email: ${ }^{*}$ Olimjon5008@mail.ru

How to cite this paper: Sharipov, K., Akhmedxodjayev, K., Tojiboyev, M. and Sarimsakov, O. (2020) The Mathematical Model of Seed Movement on a Concave Profile Rib. Engineering, 12, 216-227. https://doi.org/10.4236/eng.2020.123017

Received: December 3, 2019

Accepted: March 27, 2020

Published: March 30, 2020

Copyright (c) 2020 by author(s) and Scientific Research Publishing Inc. This work is licensed under the Creative Commons Attribution International License (CC BY 4.0).

http://creativecommons.org/licenses/by/4.0/

\begin{abstract}
The differential equations of movement along the concave profile of the grate, consisting of three broken lines, are integrated on Maple 9.5 under initial conditions, using separate functions, and graphs of the dependence of movement and speed over time are presented. The graphs show the patterns of change in displacement and speed at different angles, friction coefficient of seeds along grate with a broken line of a concave profile.
\end{abstract}

\section{Keywords}

Ginning of Cotton, Saw Gin Stand, Roll Box, Seed Roll, Rib, Concave, Cotton Seed

\section{Introduction}

Currently, the quality of fiber obtained at cotton processing enterprises depends on the efficient operation of machines operating in the direct technological process. Each process is to some extent important in obtaining high-quality fiber. The main technological process in the production of fiber at the enterprise is the process of ginning (separation of fiber from seed). The cotton, peeled from small and large litter in the cleaning workshops, is fed to the main machine of the genie shop with saw gin. The cotton enters the working chamber of the gin and is hooked with the teeth of the saws rotating next to the seed comb, leading to the grate. In the working chamber, the cotton flies hooked with the teeth saw, hook the other cotton flies and create a raw roller. The seed roll rotates in the opposite direction of the saw cylinder, and provides a continuous supply of cotton fiber to the teeth of the saws. Gin problems were previously studied by many researchers [1]-[7].

There are also known attempts by the authors of mathematical modeling of 
various stages of the technology of primary processing of cotton, which are published both in local and foreign scientific journals [8] [9] [10] [11] [12].

The authors of the article conducted a series of studies to improve the working elements of gin. The aim of the study is to create the possibility of timely exit of bare seeds from the working chamber of the saw gin by creating grooves in the grates, creating a device that performs this process, determining the technological dimensions that ensure efficient operation, as well as introducing the device into production.

The selection of the optimal structural and technological parameters of the new grate is a crucial stage of research. The use of mathematical methods in research planning, in contrast to traditional methods of research calculations, makes it possible to determine the influence of each factor together influencing several parameters on optimization parameters. As a result of this, a mathematical model of the studied object will be obtained with a relatively small multiplicity of tests. This model is also used for decision making.

Investigation of the movement of single and systemic seeds along grates with a concave profile.

1) The movement of a single seed.

To describe the movement of the seed, it is necessary to determine the concavity of the grate groove. Typically, this concavity profile consists of a curve, the shape of which should provide the minimum resistance force and the process of maximum separation of the fiber from the seed when the seeds move. Suppose the equation of the concavity profile parameter, and the shape is expressed by a curved line in the plane (Figure 1).

In this case, its curvilinear motion will be expressed by the following equations:

$$
\left\{\begin{array}{l}
m \cdot \frac{\mathrm{d}^{2} S}{\mathrm{~d} t^{2}}=\sum F_{n \tau} \\
\frac{m v^{2}}{\rho}=\sum F_{n u}^{(a)}+N
\end{array}\right.
$$

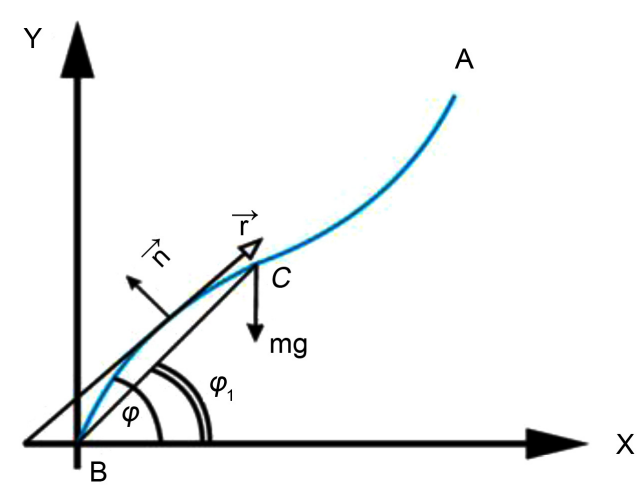

Figure 1. The movement of the seed along the rib with a concave profile. 
There is $S=S(t)$-the law of movement of the seed in concavity;

$\rho$-radius of curvature;

$F_{n \tau}$ and $F_{n u}-$ projections of external forces to the curve in the tangent and normal directions;

$N$-normal reaction force affecting the mass.

Consider the equation in the polar coordinate system. We consider the equation of the curve of the line in the coordinate of the pole systems. The law of motion of the seed is written as follows:

$$
\left.\begin{array}{l}
m \frac{\mathrm{d}^{2} S}{\mathrm{~d} t_{i}^{2}}=T \\
N=\frac{m v^{2}}{p}-m g \cos \psi
\end{array}\right\}
$$

$\psi$-the angle formed by the tangent to the curve of the line with the axis $o x$, this angle is expressed as follows:

$$
\left.\begin{array}{l}
\operatorname{tg} \psi=\frac{\frac{\mathrm{d} y}{\mathrm{~d} \varphi}}{\frac{\mathrm{d} x}{\mathrm{~d} \varphi}}=\frac{\dot{r} \sin \varphi+r \cos \varphi}{\dot{r} \cos \varphi-r \sin \varphi} \\
\sin \psi=\frac{\operatorname{tg} \psi}{\sqrt{1+\operatorname{tg}^{2} \psi}}=\frac{\dot{r} \sin \varphi+\cos \varphi}{\sqrt{r^{2}+\dot{r}^{2}}} \\
\cos \psi=\frac{\dot{r} \cos \varphi-r \sin \varphi}{\sqrt{r^{2}+\dot{r}^{2}}}
\end{array}\right\}
$$

For the radius of curvature we obtain the following expression

$$
\rho=\frac{\left(r^{2}+r^{12}\right)^{312}}{r^{2}+2 r^{12}-r r^{1}}
$$

In Equation (2), the letter indicates the sum of the tangential forces affecting the seed. In this direction, the projection of gravity and the Coulomb friction force in the direction, i.e.

$$
T=f N+m g \sin \psi
$$

If we write Equation (2) taking into account the expressions and for, we obtain the following equation:

$$
\begin{aligned}
m \ddot{S}= & \frac{m g}{\sqrt{r^{2}+r^{12}}}[\dot{r} \cos \varphi+r \cos \varphi+f(\dot{r} \cos \varphi-r \sin \varphi)] \\
& -f m \dot{S}^{2} \frac{r^{2}+2 r^{12}-r \ddot{r}}{\sqrt{r^{2}+r^{12}}}
\end{aligned}
$$

In this equation using equality $\dot{S}=\dot{\varphi} \sqrt{r^{2}+r^{12}}$, for the angle $\varphi=\varphi(t)$ we can write the following nonlinear differential equation of the second order:

$$
\begin{aligned}
& {\left[-\ddot{\varphi} \sqrt{r^{2}+r^{12}}+\dot{\varphi}^{2} \frac{r^{1}\left(r+r^{11}\right)}{\sqrt{r^{2}+r^{12}}}\right]} \\
& =\frac{g(\dot{r} \sin \varphi+r \cos \varphi)+f(\dot{r} \cos \varphi-r \sin \varphi)}{\sqrt{r^{2}+\dot{r}^{2}}}-f \dot{\varphi}^{2}\left(r^{2}+2 \dot{r}^{2}-\dot{r}^{1} \sqrt{r^{2}+\dot{r}^{2}}\right)
\end{aligned}
$$


The initial equations of this equation $\varphi(0)=\varphi_{0}$ and $\dot{\varphi}(0)=\dot{\varphi}_{0} \quad$ (6) the differential equation are integrated numerically under the above initial conditions.

The particular case (Figure 2):

The lengths of the convex grate $l_{1}, l_{2}, l_{3}$ are replaced by three straight lines $B D, D C$ and $C A$.

Enter the direct Cartesian coordinates for the moving seed in each plot

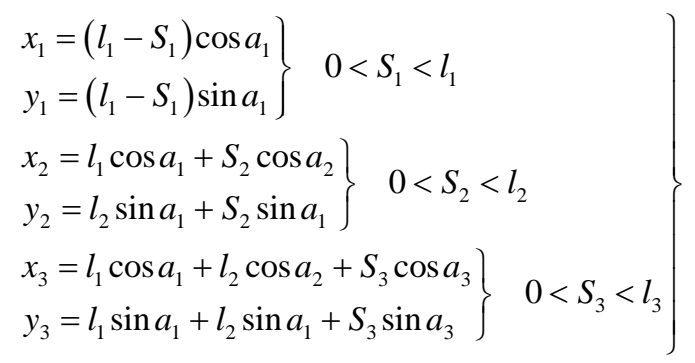

We can write the differential equation of motion $S=S(t)$ of the path covered by the seed for each section as follows:

$$
\begin{cases}m \ddot{S}_{1}=m g\left(\sin a_{1}-f \cos a_{1}\right) & 0<t<t_{1} \\ m \ddot{S}_{2}=m g\left(\sin a_{2}-f \cos a_{2}\right) & t_{1}<t<t_{2} \\ m \ddot{S}_{3}=m g\left(\sin a_{3}-f \cos a_{3}\right) & t_{2}<t<t_{3}\end{cases}
$$

Equations (8)-(10) are integrated under the following initial conditions

$$
\left.\begin{array}{ll}
S_{1}(0)=0 & \dot{S}_{1}(0)=\vartheta_{1} \\
S_{2}\left(t_{1}\right)=0 & \dot{S}_{2}\left(t_{1}\right)=\vartheta_{2} \\
S_{2}\left(t_{2}\right)=0 & \dot{S}_{2}\left(t_{2}\right)=\vartheta_{3}
\end{array}\right\}
$$

Here $t_{1}, t_{2}, t_{3}, v_{2}, v_{3}, \cdots$ To do this, consider each period of time.

a) $0<t<t_{1}$-at this time, the seed moves only along the line $A B$ and from Equation (2) under the conditions $S_{1}(0)=0, \dot{S}_{1}(0)=v_{h}$ the integral will be in the following form:

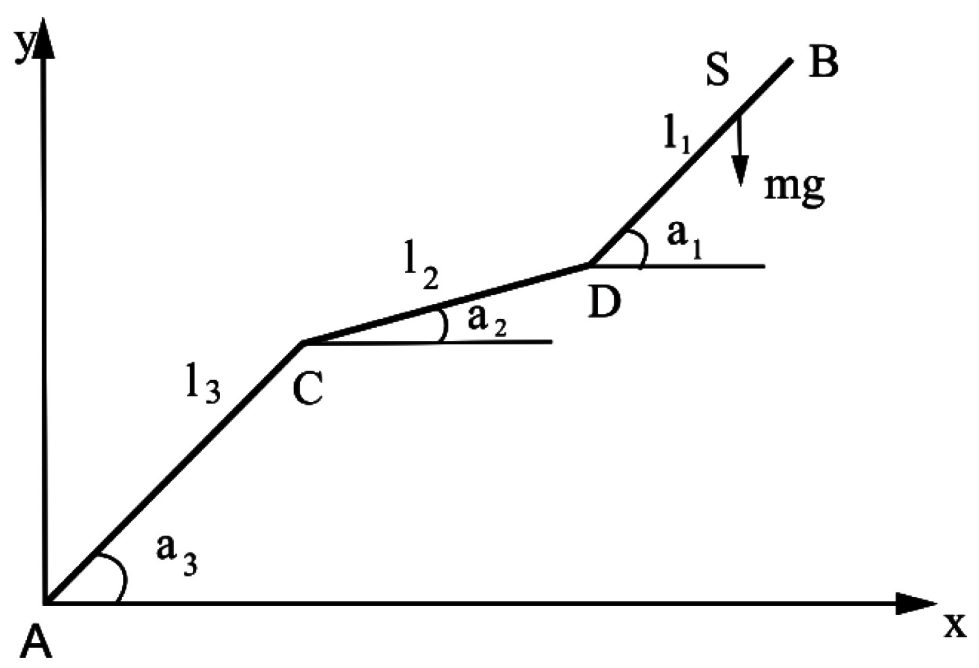

Figure 2. Profile view of a rib with 3 broken straight lines. 


$$
\begin{gathered}
S_{1}=C_{1} \frac{t^{2}}{2}+v_{h} t \\
\left(C_{1}=\sin a_{1}-f \cos a_{1}\right)
\end{gathered}
$$

Here $v_{h}=\sqrt{2 g h}, h$-is the height from the center of gravity of the seed to the bulge of the grate.

In Equation (12), taking into account the equation $S_{1}=l_{1}$, we obtain the equation with respect to $t_{1}$

$$
\begin{aligned}
& C_{1} t_{1}+2 v_{n} t_{1}-l_{1}=0 \\
& l_{1}=c \cdot \frac{t^{2}}{2}+v_{h} \cdot t \Rightarrow
\end{aligned}
$$

Here we define $t=t_{1}$.

As a result, we obtain the expression of speed $v_{1}$

$$
v_{1}=c_{1} t_{1}+v_{h}
$$

Similarly, we obtain the following solutions for the second and third sections

$$
\begin{gathered}
\left.\mid \begin{array}{l}
S_{2}=c_{2} \frac{\left(t-t_{1}\right)^{2}}{2}+\vartheta_{2}\left(t-t_{1}\right) \\
\vartheta_{2}=\vartheta_{1} \cos a_{1} \\
c_{2}=\sin a_{2}-f \cos a_{2}
\end{array}\right\} \\
\left.\begin{array}{l}
S_{3}=c_{3} \frac{t-t_{2}}{2}+\vartheta_{3}\left(t-t_{2}\right) \\
\vartheta_{3}=\vartheta_{2} \cos a_{2} \\
c_{3}=\sin a_{3}-f \cos a_{3}
\end{array}\right\}
\end{gathered}
$$

2) Assume that the sections of the transition $A B, B C$ and $C A$ the convex grate are expressed by circular arcs (Figure 3 ).

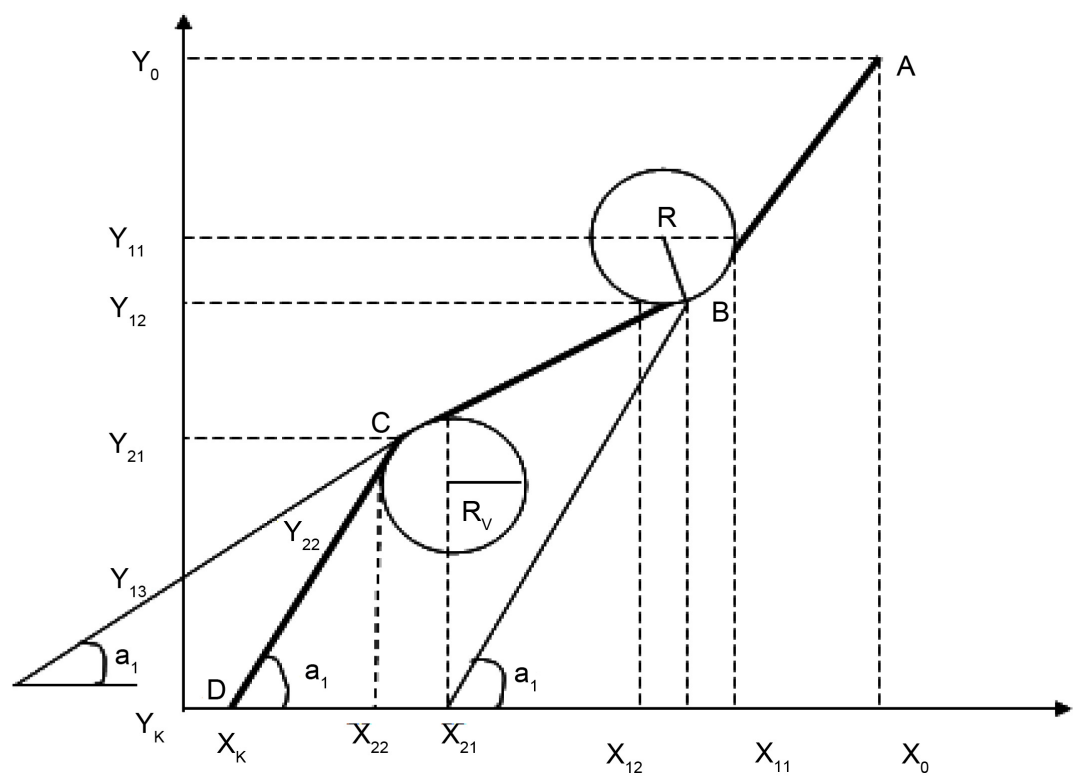

Figure 3. Coordinates of the characteristic points of the rib. 
We write the equations of arcs in the following form

$$
\left.\begin{array}{l}
\left(x-x_{1}\right)^{2}+\left(y-y_{1}\right)^{2}=R_{1}^{2} \\
\left(x-x_{2}\right)^{2}+\left(y-y_{2}\right)^{2}=R_{i}
\end{array}\right\}
$$

Here $x_{i} ; y_{i}$-coordinates of the centers of arcs; $R_{i}$-radius of arcs.

Equations of straight lines, $A B, B C$ and $C D$.

$$
\left.\begin{array}{l}
y_{1}=k_{1}\left(x-x_{11}\right)+y_{11} \\
y_{2}=x_{2}\left(x-x_{12}\right)+y_{12} \\
y_{3}=x_{3}\left(x-x_{13}\right)+y_{13}
\end{array}\right\}
$$

Points $x_{11}, y_{11}$ lie on an arc, therefore

$$
\left(x_{11}-x_{1}\right)^{2}+\left(y_{11}-y_{1}\right)^{2}=R_{i}^{2}
$$

In addition, the slope of the line $A B$

$$
K_{1}=\frac{x_{11}-x_{1}}{\sqrt{\left(x_{11}-x_{1}\right)^{2}+\left(y_{11}-y_{1}\right)^{2}}}=\operatorname{tg} a_{1}
$$

If the angle coefficient $K_{1}$ is given, the coordinates $x_{11}$ and $y_{11}$ are also determined in Equations (18) and (20).

The coordinates $x_{12}$ and $y_{12}$

$$
\begin{gathered}
\left(x_{12}-x_{1}\right)^{2}+\left(y_{12}-y_{1}\right)^{2}=R_{i} \\
K_{2}=\frac{x_{12}-x_{1}}{\sqrt{\left(x_{12}-x_{1}\right)^{2}+\left(y_{12}-y_{1}\right)}}=\operatorname{tg} a_{2} \\
K_{3}=\frac{\left(x_{21}-x_{2}\right)^{2}+\left(y_{21}-y_{2}\right)^{2}=R_{i}^{2}}{\sqrt{\left(x_{22}-x_{2}\right)^{2}+\left(x_{22}-y_{2}\right)^{2}}}=\operatorname{tg} a_{3}
\end{gathered}
$$

From each Equations (20)-(24) unknown coordinates are determined $x_{11}$, $y_{11} ; x_{12}, y_{12} ; x_{21}, y_{21} ; x_{22}, y_{22}$. The equation for the convexity of the grate will be in the form

$$
\begin{array}{ll}
y=K_{1}\left(x-x_{11}\right)+y_{11} & x_{0}<x<x_{11} \\
y=y_{1}-\sqrt{R_{i}^{2}-\left(x-x_{1}\right)^{2}} & x_{11}<x<x_{12} \\
y=K_{2}\left(x-x_{21}\right)+y_{21} & x_{12}<x<x_{22} \\
y=y_{2}-\sqrt{R_{i}^{2}-\left(x-x_{2}\right)^{2}} & x_{21}<x<x_{22} \\
y=k_{3}\left(x-x_{22}\right)+y_{22} & x_{22}<x<x_{12}
\end{array}
$$

We write the equation of motion of the seed for each plot (Figure 4)

$$
\left.\begin{array}{ll}
m \ddot{x}=m g\left(\sin a_{1}-f \cos a_{1}\right) & 0<t<t_{1} \\
m \ddot{x}=m g\left(\sin a_{2}-f \cos a_{2}\right) & t_{1}<t<t_{2} \\
m \ddot{x}=m g\left(\sin a_{3}-f \cos a_{3}\right) & t_{2}<t<t_{3}
\end{array}\right\}
$$




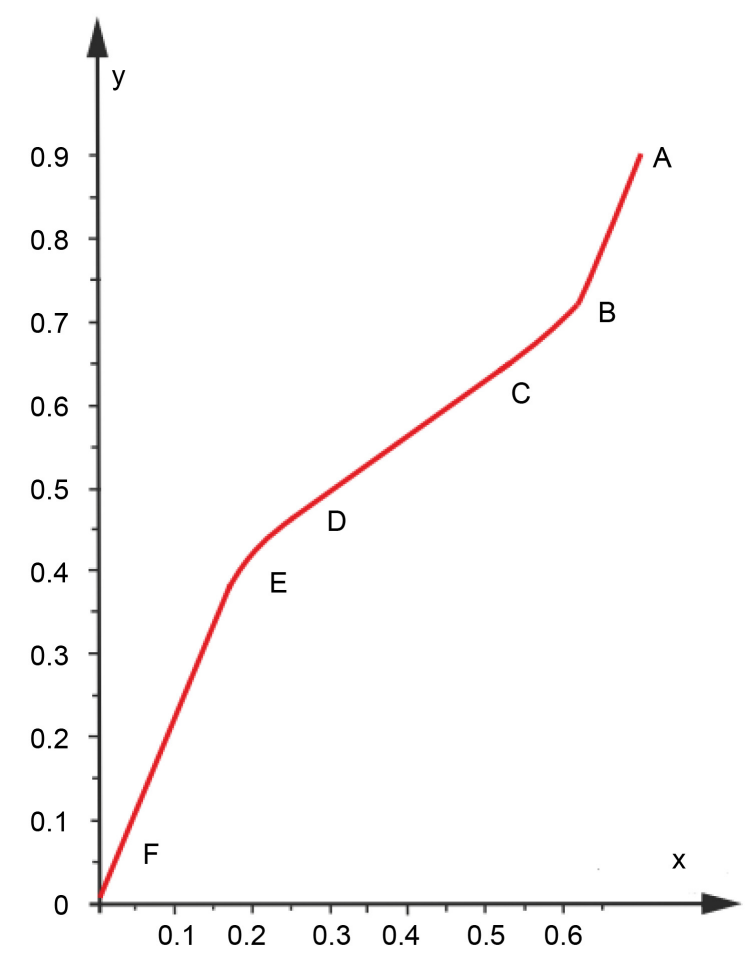

Figure 4. The view of the grate with a concave surface in the plane (x:y).

The differential equations of movement of along the concave profile of the grate, consisting of three broken lines, is integrated on Maple 9.5 under initial conditions, using separate functions, and graphs of the dependence of movement and speed over time are presented (Figures 5-10).

Figure 5 and Figure 6 show the nature of the change in the path and speed of the seeds with time $t$ for various friction coefficients in the aircraft section, for various values of the friction coefficient: $1-f=0.03 ; 2-f=0.06 ; 3-f=0.09$, in which all graphs are upward.

Figure 7 and Figure 8 show the nature of the change in the path and speed of passage of seeds with time $t$ at various friction coefficients in the SD section: $1-f=$ $0.03 ; 2-f=0.06 ; 3-f=0.09$, which also have an upward character of change.

Figure 9 and Figure 10 show the nature of the change in the speed of seeds along the trajectory $s$ for various friction coefficients in the $\mathrm{DE}$ and $\mathrm{EF}$ sections for various friction coefficients $1-f=0.03 ; 2-f=0.06 ; 3-f=0.09$, where the growth rate of parameters in the $\mathrm{EF}$ region is much higher than in the previous one.

The graphs show the patterns of change in displacement and speed at different angles, friction coefficient of seeds along grate with a broken line of a concave profile.

The analysis showed the feasibility of using ribs with a concave profile, which helps to accelerate the release of seeds from the working chamber of the fiber separator, which significantly increases the productivity of the cotton processing. 


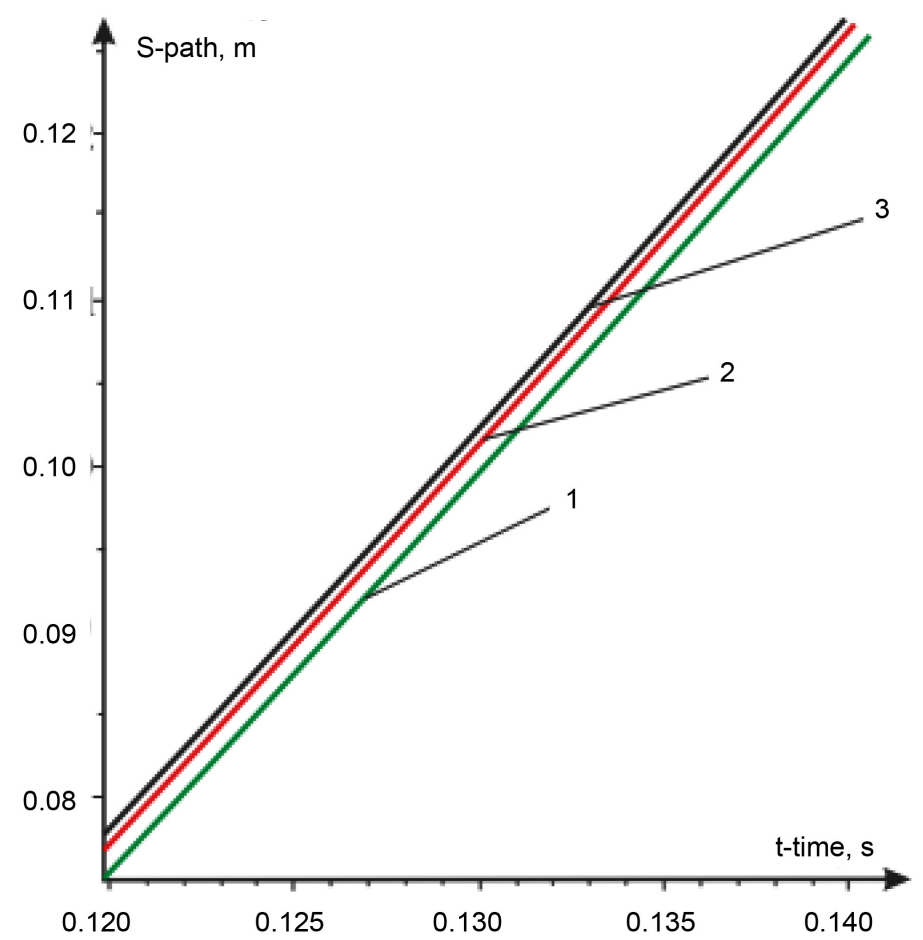

Figure 5. The pattern of change in the path of the seed over time $t$ at various friction coefficients in the plot $\mathrm{BC}: 1-f=0.03 ; 2-f=0.06 ; 3-f=$ 0.09 .

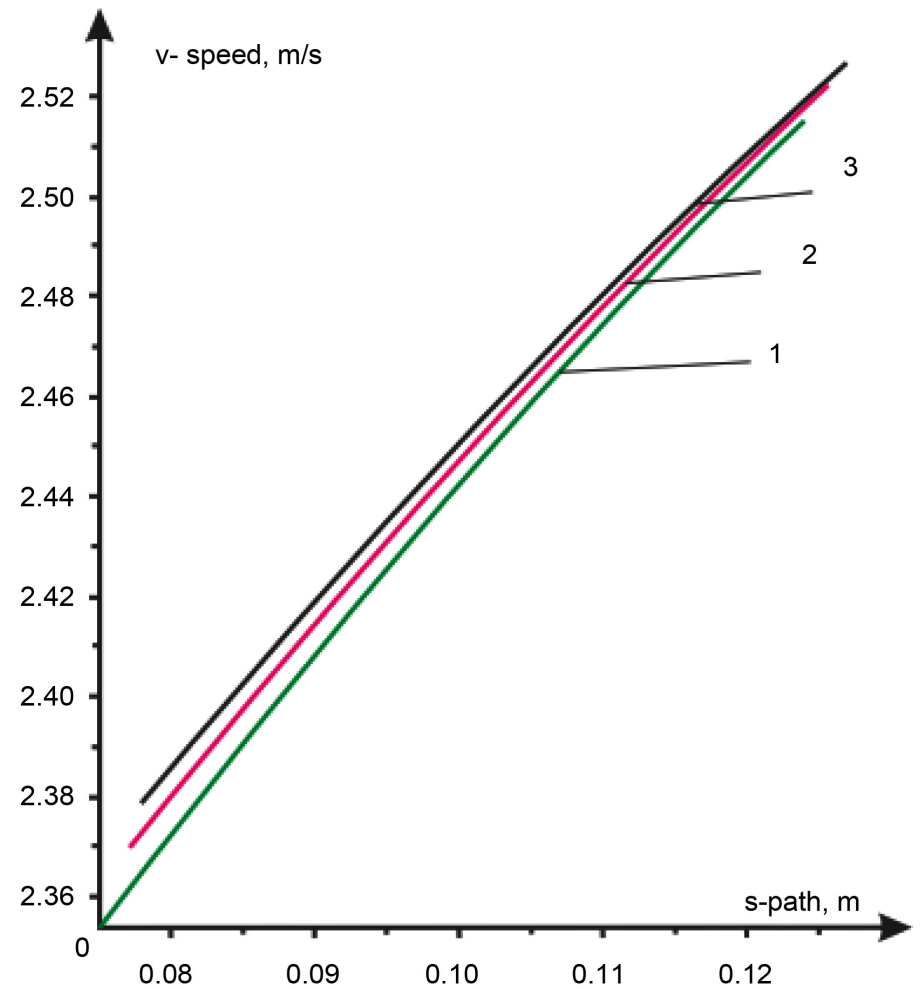

Figure 6. The pattern of change in the path of the seed over time $t$ at various friction coefficients in the plot $\mathrm{BC}: 1-f=0.09 ; 2-f=0.06 ; 3-f=$ 0.03 . 


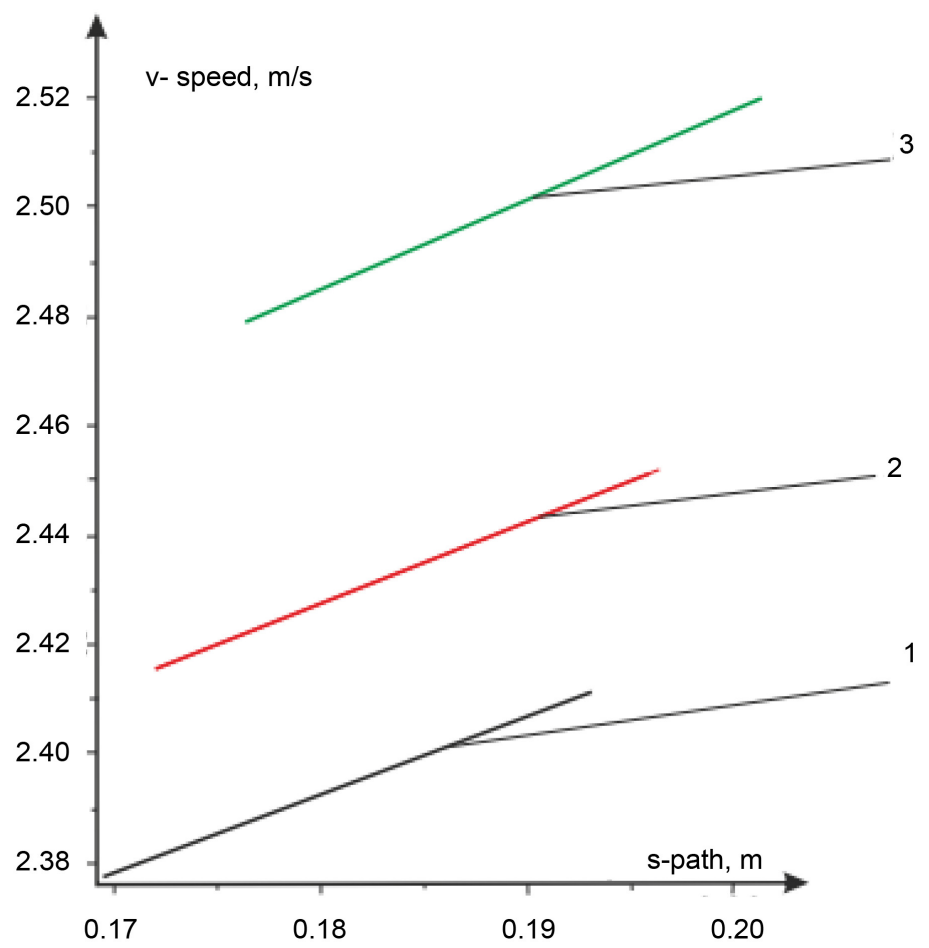

Figure 7. The pattern of change in the path of the seed over time $t$ at various friction coefficients in the plot СД: $1-f=0.03 ; 2-f=0.06 ; 3-f=$ 0.09 .

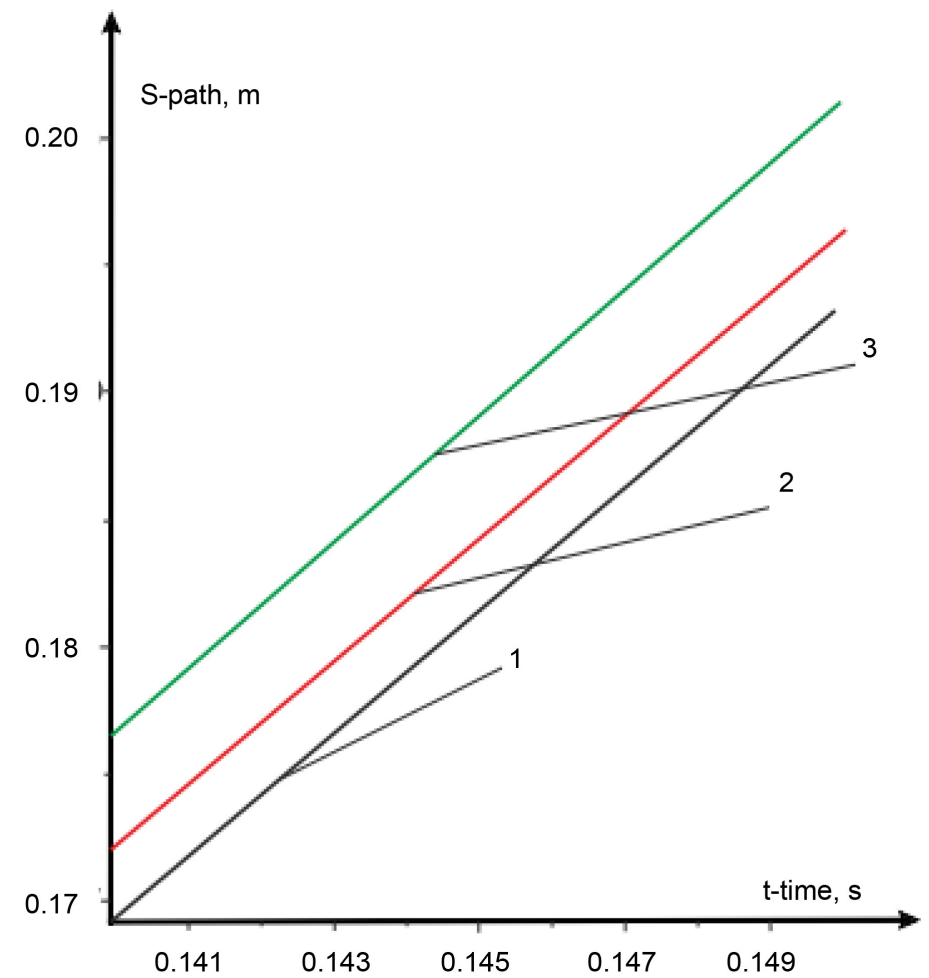

Figure 8. The pattern of change in the path of the seed over time $t$ at various friction coefficients in the plot СД: $1-f=0.03 ; 2-f=0.06 ; 3-f=$ 0.09 . 


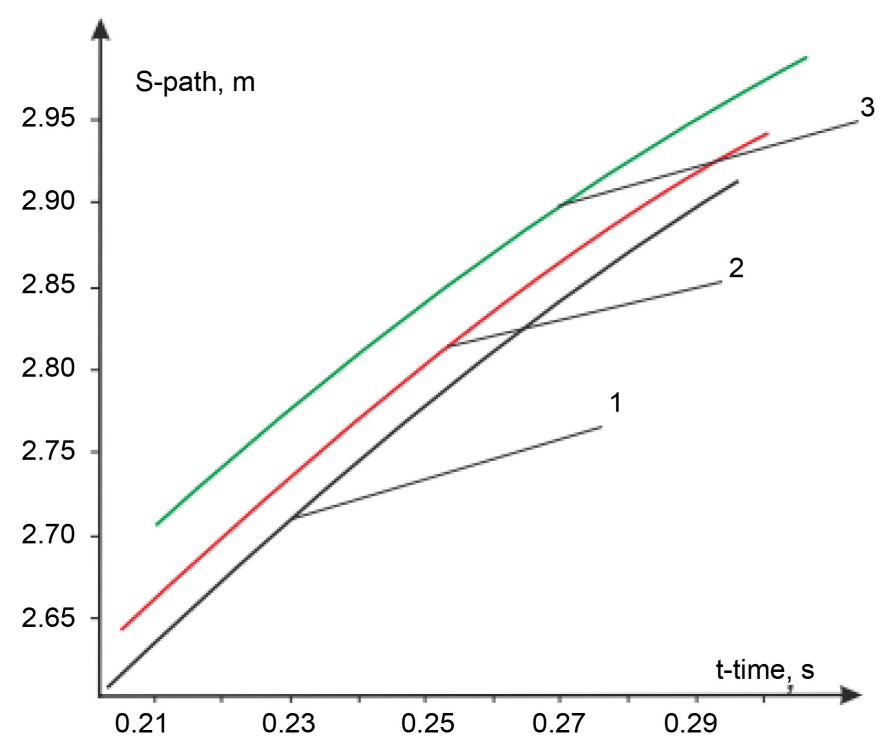

Figure 9. The pattern of change in seed speed along the path $s$ at various friction coefficients in the plot ДЕ: $1-f=0.03 ; 2-f=0.06$; $3-f=0.09$.

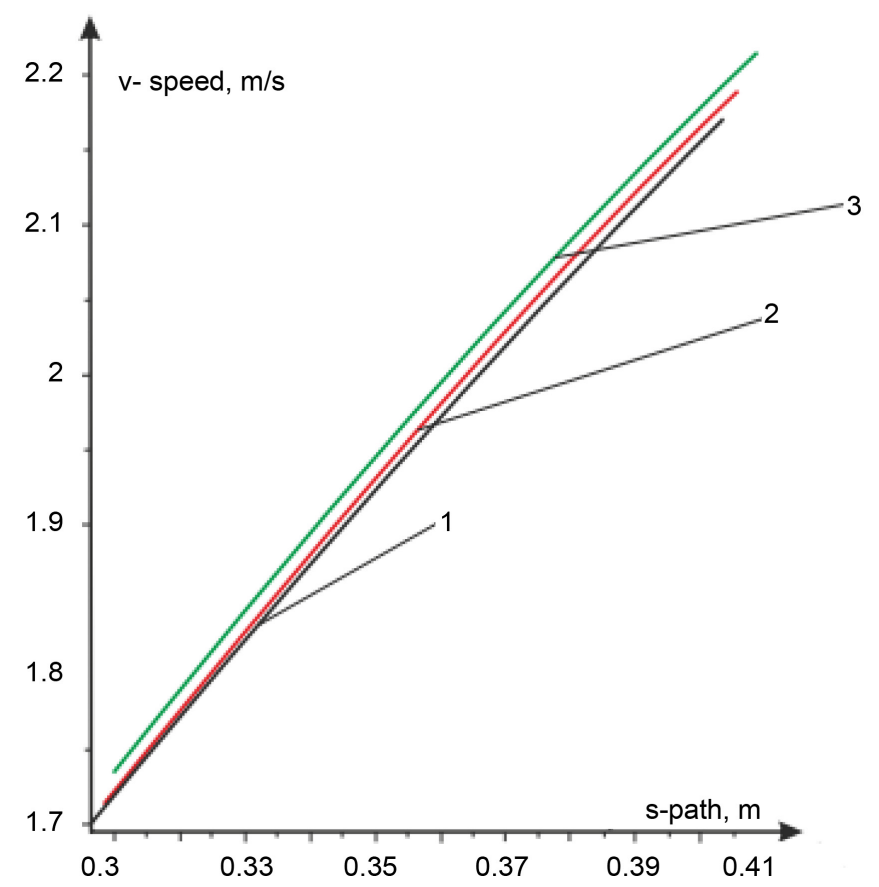

Figure 10. The pattern of change in seed speed along the path $s$ at various friction coefficients in the plot $\mathrm{EF}: 1-f=0.03 ; 2-f=0.06$; $3-f=0.09$.

\section{Conclusions}

1) An increase in the coefficient of friction leads to a decrease in the movement and speed of the seed in time.

2) You can see that in this section the trajectory and speed of the seeds depend on the friction coefficient, that is, with an increase in the friction coefficient, the 
speed decreases.

3) From the above graphs, it is possible to determine the tilt angles $\alpha_{1}=65^{\circ}, \alpha_{2}=25^{\circ}, \alpha_{3}=45^{\circ}$ for the concave grate model with broken, the values of which were accepted, and the grates were tested under production conditions.

4) Determining the movement and speeds of seeds along the grate with a concave profile makes it possible to improve-accelerate the exit of seeds from the roll box of the gin.

\section{Conflicts of Interest}

The authors declare no conflicts of interest regarding the publication of this paper.

\section{References}

[1] Sarimsakov, A., Karimov, A.I. and Murodov, R. (2012) Static Calculation of Processes in the Roll Box of the Saw Gin. Problems of Mechanics, No. 2, .17-23.

[2] Akhmedkhodjaev, K.T., Karimov, A.I., Tojiboyev, M. and Sharipov, H. (2013) Determination of the Static Balance of Forces Affecting Seeds Moving along Grates with a Convex Profile. Scientific and Technical Journal of the Ferghana Polytechnic Institute, No. 2, 42-45.

[3] Akhmedkhodjaev, K.T., Karimov, A.I., Tojiboyev, M. and Sharipov, H. (2018) Theoretical Analysis of the Movement of Seeds along the Grate with a Convex Profile. Scientific and Technical Journal of the Ferghana Polytechnic Institute, No. 3, 35-39.

[4] Karimov, A.I., Azizov, S. and Ismanov, M. (2014) Mathematical Modeling of the Technological Processes Original Processing of Cotton. International Journal of Innovation and Applied Studies, 6, 28-39. http://www.ijias.issr-journals.org

[5] Akramjon, S., Rustam, M., Akmal, U. and Dilmurat, K. (2018) Movement Differential Equation of Seed Roller Which Has Been Installed Stake Accelerator on the Roll Box of Gin Machine. Engineering, 10, 521-529. https://doi.org/10.4236/eng.2018.108038

[6] Akmal, U., Khamit, A., Akramjon, S. and Muazzam, K. (2018) The Saw Gin Stand with Adjustable Movement of the Roll Box. Engineering, 10, 486-494. https://doi.org/10.4236/eng.2018.108034

[7] Khamit, A., Akmal, U. and Kamola, O. (2019) Investigation of the Ginning Process on DП Series Saw Gin Stands. Engineering, 11, 523-530.

https://www.scirp.org/journal/eng https://doi.org/10.4236/eng.2019.118036

[8] Obidov, A., Akhmedkhodjaev, Kh., Sarimsakov, O. and Holikov, Q. (2018) Investigation of the Properties of Fibrous Cotton Seeds, for Sorting on a Mesh Surface. Engineering, 10, 572-578. https://doi.org/10.4236/eng.2018.109041

[9] Abdukarimovich, M.O., Ibragimovich, A.K. and Sharipjanovich, S.O. (2018) Designing a New Design of a Loading Cylinder for Pneumo-Mechanical Spinning Machines. Engineering, 10, 345-356. https://doi.org/10.4236/eng.2018.106025

[10] Sarimsakov, O. and Gaybnazarov, E. (2016) About Energy Consumption in Pneumatic Conveying of Raw Cotton. American Journal of Energy and Power Engineering, 3, 26-29.

[11] Sarimsakov, O., Xusanov, C. and Muradov, R. (2016) The Change in Air Pressure 
along the Length of the Pipeline Installation for Pneumatic Conveying of Raw Cotton. Journal of Engineering and Technology, 3, 89-92.

http://www.aascit.org/journal/et

[12] Sarimsakov, O. (2016) The Possibility of Reducing Cotton Consumption in Cotton. American Journal of Science and Technology, 4, 68-72.

http://www.aascit.journal/ajst 